\section{SANDIA REPORT}

SAND95-3016/1 • UC-630

Unlimited Release

Printed January 1996
RECEIVED

JAN 251996

OSTI

\title{
Fuzzy Logic and a Risk-Based Graded Approach for Developing S/RIDs: an Introduction
}

\author{
J. R. (Bob) Wayland
}

\section{Prepared by}

Sancia National Laboratories

Abuquerque, New Mexico 87185 and Livermore, Calfifornia 94550

for the United States Department of Energy

under Contract DE-ACO4-94AL85000

Approved for public release; distribution is unlimited.
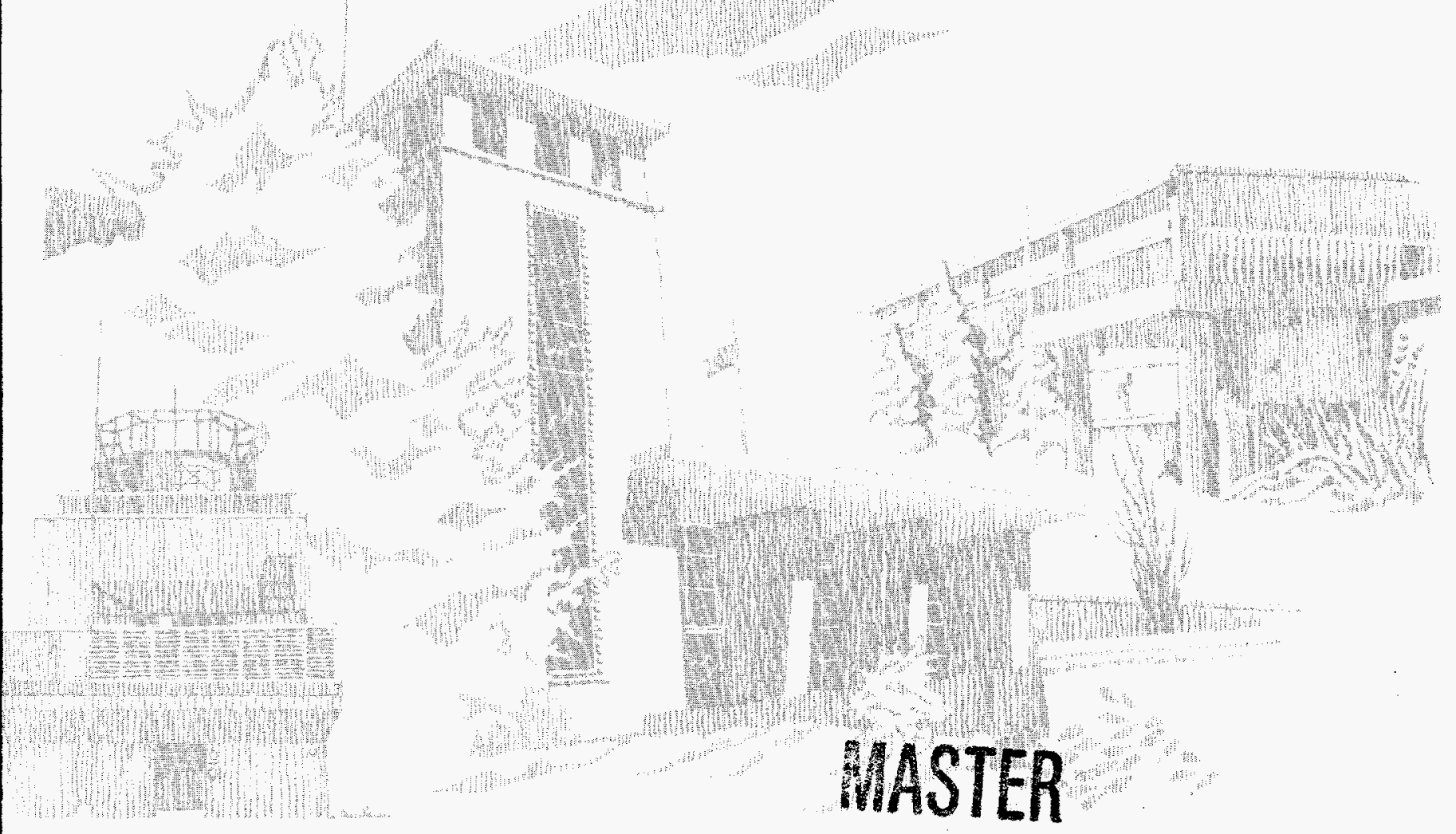
Issued by Sandia National Laboratories, operated for the United States Department of Energy by Sandia Corporation.

NOTCB: This report was prepared as an account of work sponsored by an agency of the United States Government. Neither the United States Government nor any agency thereof, nor any of their employees, nor any of their contractors, subcontractors, or their employees, makes any warranty, express or implied, or assumes any legal liability or responsibility for the accuracy, completeness, or usefulness of any information, apparatus, product, or process disclosed, or represents that its use would not infringe privately owned rights. Reference herein to any specific commercial product, process, or service by trade name, trademark, manufacturer, or otherwise, does not necessarily constitute or imply its endorsement, recommendation, or favoring by the United States Government, any agency thereof or any of their contractors or subcontractors. The views and opinions expressed herein do not necessarily state or reflect those of the United States Government, any agency thereof or any of their contractors.

Printed in the United States of America. This report has been reproduced directly from the best available copy.

Available to DOE and DOE contractors from

Office of Scientific and Technical Information

PO Box 62

Oak Ridge, TN 37831

Prices available from (615) 576-8401, FTS 626-8401

Available to the public from

National Technical Information Service

US Department of Commerce

5285 Port Royal Rd

Springfield, VA 22161

NTIS price codes

Printed copy: A03

Microfiche copy: A01 


\section{DISCLAMMER}

Portions of this document may be illegible in electronic image products. Images are produced from the best available original document. 
SAND $95-3016 / 1$

Distribution

Unlimited Release

Category UC-630

Printed January 1996

\title{
Fuzzy Logic and a Risk-Based Graded Approach
}

\author{
for Developing S/RIDs:
}

\author{
an Introduction
}

\author{
J. R. (Bob) Wayland \\ Product Assurance \\ Sandia National Laboratories \\ Albuquerque, NM 87185
}

\begin{abstract}
A Standards/Requirements Identification Document (S/RID) is the set of expressed performance expectations, or standards, for a facility. Critical to the development of an integrated standards-based management is the identification of a set of necessary and sufficient standards from a selected set of standards/requirements. There is a need for a formal, rigorous selection process for the S/RIDs. This is the first of three reports that develop a fuzzy logic selection process. In this report the fundamentals of fuzzy logic are discussed as they apply to a risk-based graded approach.
\end{abstract}




\section{CONTENTS}

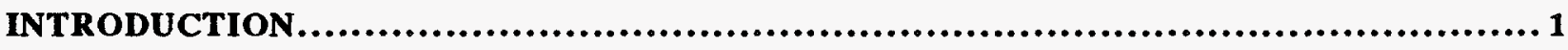
OVERVIEW OF FUZZY LOGIC.....................................................

FUZZY LOGIC OF A RISK-BASED GRADED APPROACH $\ldots \ldots \ldots \ldots \ldots \ldots \ldots \ldots \ldots \ldots \ldots \ldots$

CONCLUSION................................................................................19

REFERENCES............................................................................... 


\section{INTRODUCTION}

Sandia National Laboratories (SNL or Sandia) has submitted an Implementation Plan for the development of Standards/Requirements Identification Documents (S/RIDs) for its identified Defense Nuclear Facilities. An S/RID is an essential element of standards-based management and identifies the set of expressed performance expectations, or standards, for Sandia's Nuclear Facilities. Critical to the development of integrated standards-based management is the identification of a set of necessary and sufficient standards. The process of identification requires the evaluation of a selected set of standards/requirements. For example, everyone is aware of the requirement that procedures "should be stated simply, unambiguously and understandably, and should indicate methods to be used and the criteria to be satisfied." The vagueness of the real world imposes very real limits upon this ideal. (Think about terms like effectiveness, performance, safety, reliability, critical, etc.) Common sense allows people to overcome the vagueness of something being only partially true. Normally, they try to compensate for the lack of precision with a graded approach; but there is a lack of a firm, underlying foundation, an uncertainty, that can, and often does, get people into trouble. Luckily, a branch of mathematics exists that describes the common sense pictures of an uncertain world. It's called "Fuzzy Logic."

This is the first of three reports that will describe a technique for applying a fuzzy logicgraded approach to the choice of necessary and sufficient S/RIDs. This first report introduces the concepts of fuzzy logic and how they may be applied to define necessary and sufficient standards and requirements for SNL The second report will expand the technique, including the underlying mathematics, for development of those S/RIDs. The third report will present the $\mathrm{C}++$ program, and its user manual, for applying the technique at SNL. 


\section{OVERVIEW OF FUZZY LOGIC}

A fundamental theorem asserts that any continuous system can be modeled using fuzzy logic. The systems faced daily are continuous, with very few exceptions. Armed with this knowledge, consider the following, required background.

In traditional (classical) logic, a member of a set either does or does not belong to a specific set; there is no middle ground. A set member cannot be both a member and a nonmember at the same time. To recall an old adage, "You can't be a little dead." However, a person can be sick, or even a little sick. Consider performance, for example. If someone is playing a game of golf (or doing his job), he can be performing all the way from dead asleep at the tee to being completely committed and functioning at peak capacity. There are no clear boundaries for the stages between these two extremes. Indeed, just where one is on the spectrum of performance depends upon the time of day, the hole being played, the weather, fellow players, and almost as many other variables as one might care to name. The point is that a person can be a member of more than one set at the same time. That person can be putting very well, but not be on the green.

Another way of looking at this is to say that there is a fuzzy boundary between the levels of performance. (Great drive, fair approach, lousy putting.) If someone tried to put this into a single state, he would miss the subtleties that make golf (life) interesting. Thus, a measure of this fuzziness could be characterized by saying that the putting may be at $67 \%$ and the driving at $46 \%$. The fuzziness measure conveys how often something will happen or that some condition exists. Remember that performance is somewhere within the spectrum of allowed levels. Mathematically, this just says that if one adds up the percentages of all the sets, the sum must equal $100 \%$. 
In addition to fuzzy sets, another advantage of fuzzy logic is that it allows a person to say that an answer to a question can be partially true and partially false. The statement, "Your performance on the golf course is excellent," can be $40 \%$ true. In classical systems, the degrees of set membership are normally all-or-nothing. However, fuzzy systems and concepts are not allor-nothing. The classical set for a Fair golfer could be graphically represented by an all- inclusive box, as shown below.

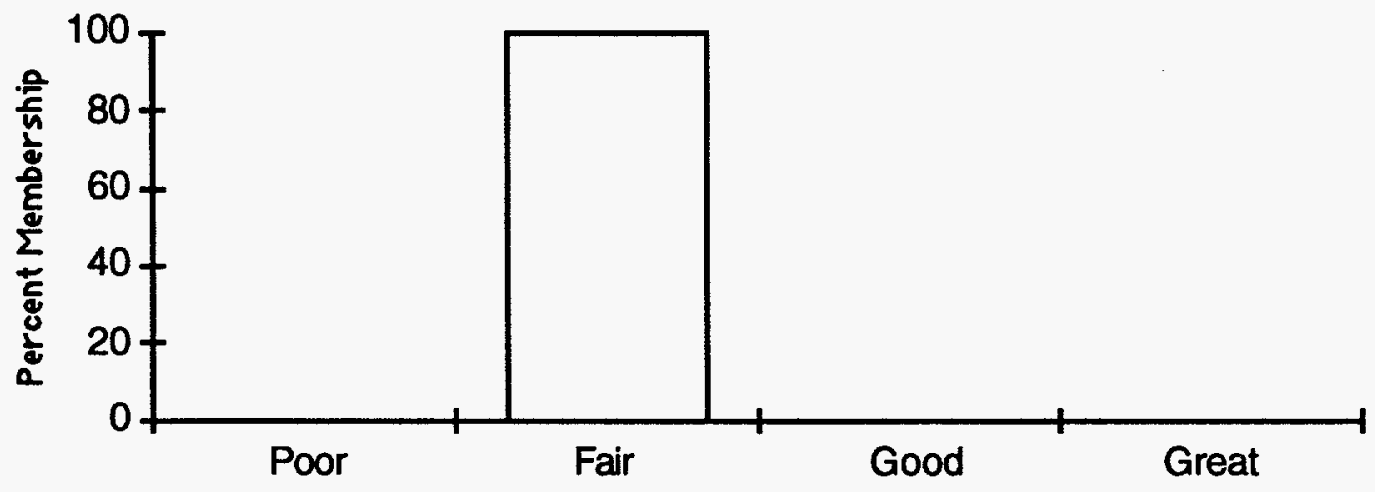

When dealing with a fuzzy set, there is no longer an all-or-nothing requirement. A partial membership in a set does not exclude partial membership in the set's complementary sets. For the golfer who is referred to as Fair, there is partial membership in either the Poor or Good complementary sets, depending upon which side of the Fair category (set) the golfer happens to be when the description is made, as shown below.

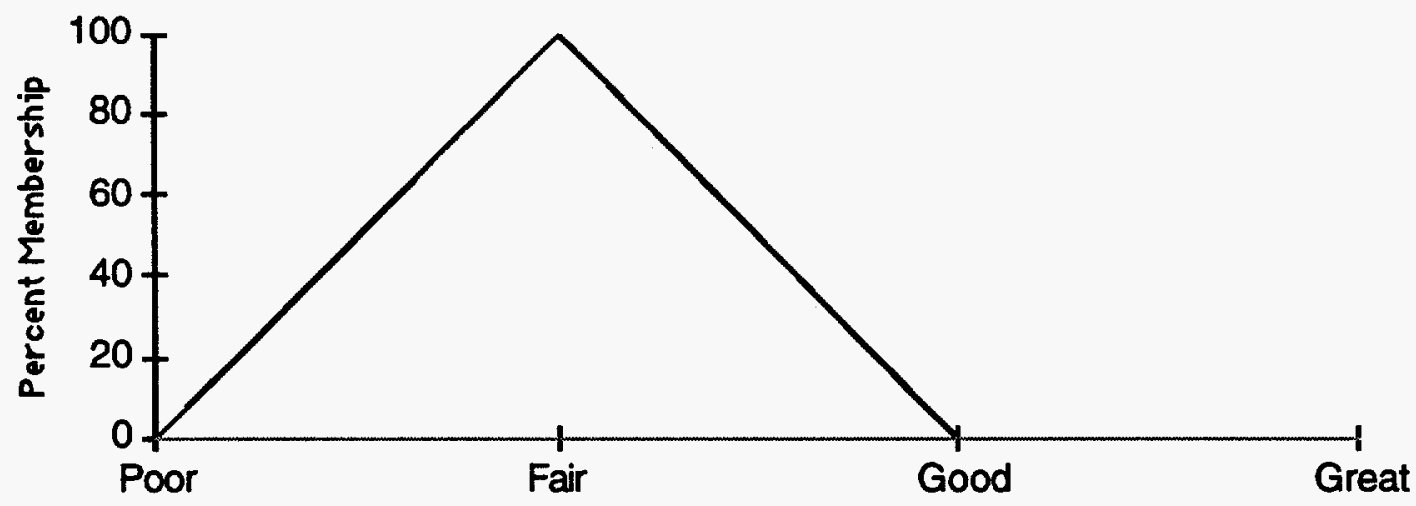


The relationship of the set Fair to its complementary sets could be drawn as:

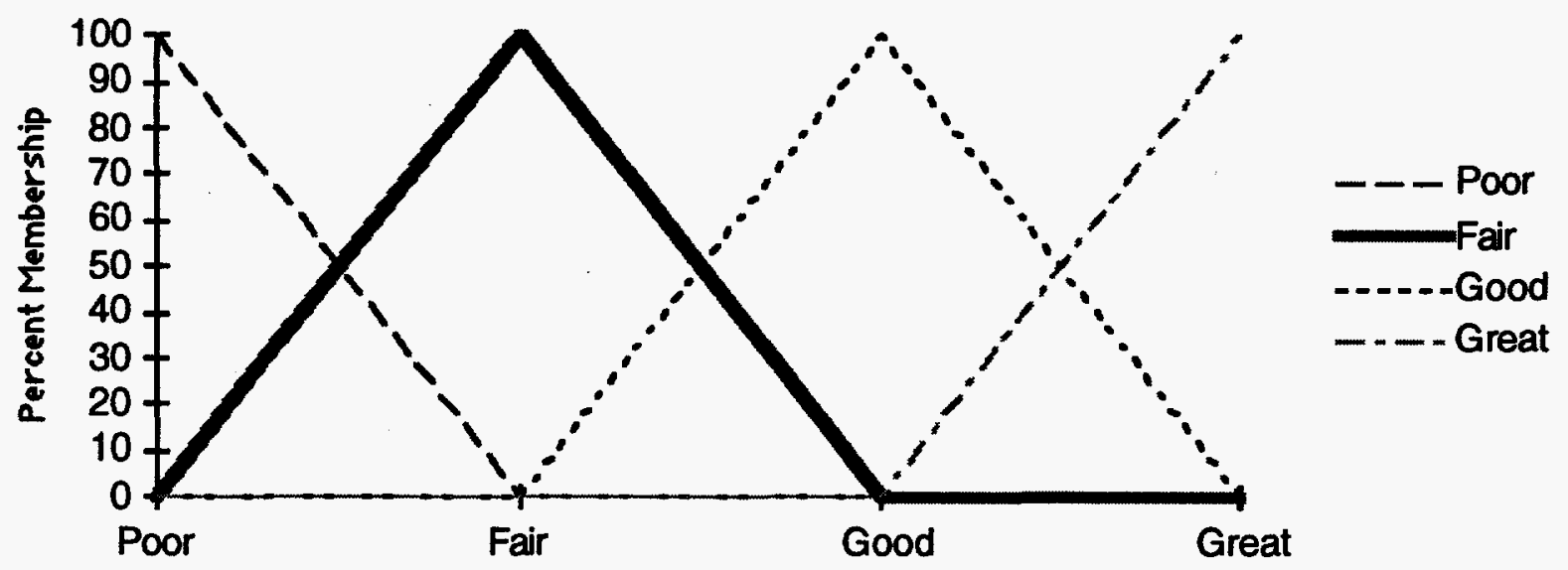

So, if the golfer is midway between Fair and Good, the membership would be $50 \%$ in the set Fair and 50\% in the set Good. Notice that the total of the two memberships must be $100 \%$. Membership functions of a variable are usually chosen so that there is an overlap with adjacent membership functions. This produces a smoothed response, regardless of the level. Of course, this can be made as complicated as needed (or wanted) by imposing a mathematical (functional) curve to the boundary between sets. In this paper, the simple, linear relationships shown are more than adequate for even the most demanding situations. (A non-linear relationship would be necessary only in extremely complex cases.) ${ }^{1}$

The application of fuzzy sets relies upon incorporating human knowledge and experience into a set of IF-THEN logical statements. The success or failure of the fuzzy logic process is established at this level. To illustrate the process, consider how one would establish whether a process, service, etc., has quality. Start with the definition:

QUALITY: The degree to which an item or process meets or exceeds the user's requirements and expectations.

To illustrate how fuzzy logic might be applied, rewrite this so that there are only two groups of fuzzy sets with which to deal:

${ }^{1}$ Refer to Practical Neural Network Recipes in C++, by T. Master, Academic Press, 1993. 
QUALITY: The degree to which an item/process (Set 1) meets or exceeds the user's requirements/expectations (Set 2).

Further, restrict the focus to the process of listening. The group of fuzzy sets describing the process of listening might be:

- ignoring the speaker (Ignoring),

- looking at but not hearing the speaker (Looking),

- hearing but not paying attention (Hearing),

- listening but not carefully (Awake),

- listening and understanding what the speaker is saying (Understanding), and

- hanging on every word (Hanging).

(Of course, there are extenuating conditions; for example, the instructor who announces that there will be a test over the material that is being covered.) This can be graphically displayed:

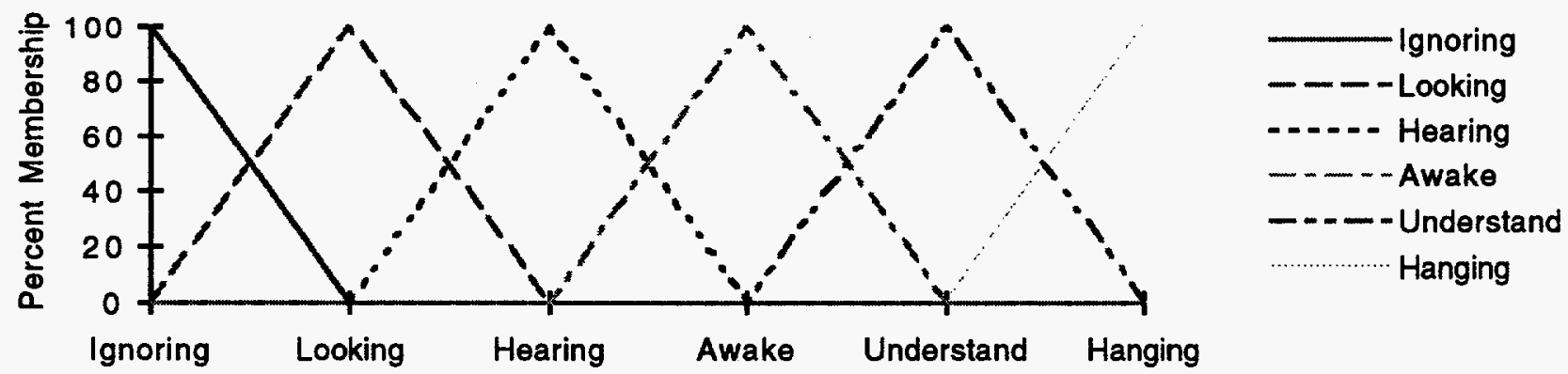

A person's attention level places him somewhere along the axis of the process of listening when attending a lecture, business meeting, etc. For example, if someone is a fourth of the way between Looking and Hearing, then he is $75 \%$ in the Looking set and $25 \%$ in the Hearing set. This produces the IF part of the IF-THEN logical statement. The rules will consist of this Premise block (called the antecedent or "IF" block) and a Conclusion block (the consequent or "THEN" block). One rule that might apply here could be stated: "IF a person is looking more than hearing, THEN that person will not understand what is being said." In addition to attention level, if ambient noise exists as an antecedent, it will also have a membership function. 
The span of the level of the noise could be characterized as being from dead silence to a total uproar, with as many sets as needed to cover the spectrum. For illustration, consider a simple example in which the scale is from Silence (say, $20 \mathrm{~dB}$ ) to Total Uproar (120 dB), in five bands of $20 \mathrm{~dB}$ each. (At the silence level, one can easily hear what is being said because the only sound is the speech. At the uproar level, though, speech could not be heard because it is drowned out.)

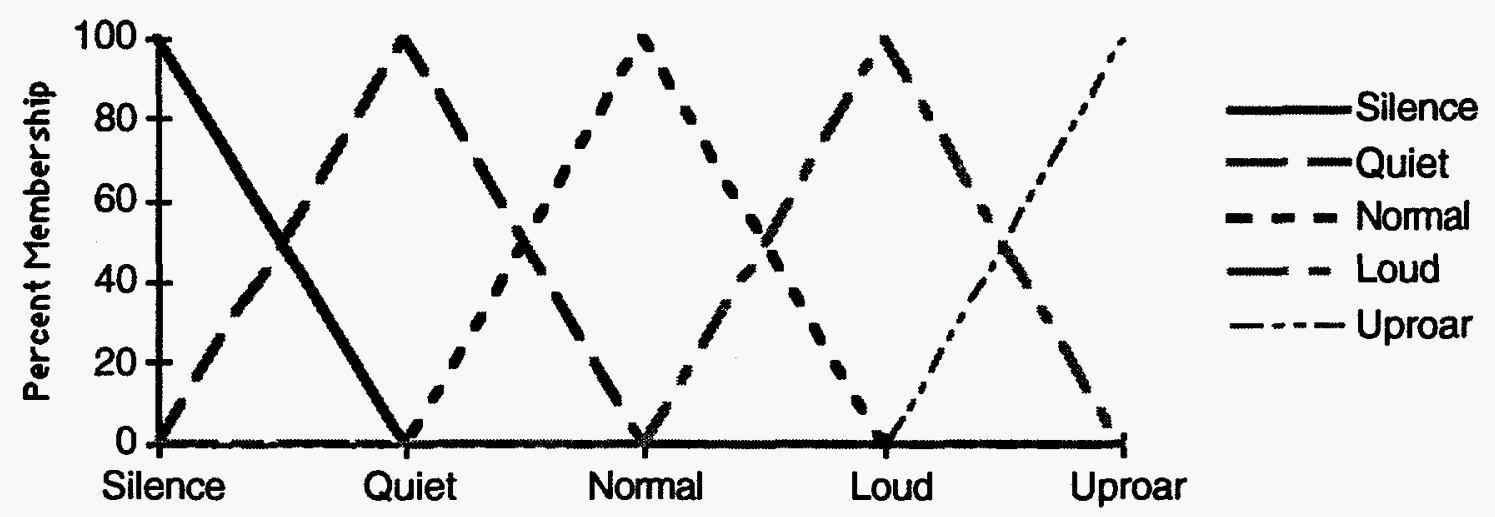

The inputs from each of the antecedents in this example are compound, requiring the additional structure of IF...AND...THEN, as illustrated in the following table on conclusion rules:

Conclusion Rules

\begin{tabular}{|c|l|l|}
\hline Rule & \multicolumn{1}{|c|}{ Premise Block } & \multicolumn{1}{|c|}{ Conclusion Block } \\
\hline 1 & $\begin{array}{l}\text { IF ignoring or just looking AND the } \\
\text { noise is any level }\end{array}$ & $\begin{array}{l}\text { THEN the listener doesn't comprehend } \\
\text { the information }\end{array}$ \\
\hline 2 & $\begin{array}{l}\text { IF hearing AND noise is normal or } \\
\text { less }\end{array}$ & $\begin{array}{l}\text { THEN the listener will get very little of } \\
\text { the information }\end{array}$ \\
\hline 3 & $\begin{array}{l}\text { IF awake AND noise is normal or } \\
\text { less }\end{array}$ & $\begin{array}{l}\text { THEN the listener will comprehend } \\
\text { about half of the information }\end{array}$ \\
\hline 4 & IF awake AND noise is loud & $\begin{array}{l}\text { THEN the listener will comprehend } \\
\text { much less than half of the information }\end{array}$ \\
\hline 5 & $\begin{array}{l}\text { IF understanding AND noise is } \\
\text { quiet to loud }\end{array}$ & $\begin{array}{l}\text { THEN the listener will comprehend } \\
\text { most of the information }\end{array}$ \\
\hline 6 & $\begin{array}{l}\text { IF hanging AND noise is quiet to } \\
\text { loud }\end{array}$ & $\begin{array}{l}\text { THEN the listener will comprehend } \\
\text { almost all of the information }\end{array}$ \\
\hline 7 & $\begin{array}{l}\text { F hanging AND noise is at uproar } \\
\text { level }\end{array}$ & $\begin{array}{l}\text { THEN the listener will comprehend } \\
\text { almost nothing of the information }\end{array}$ \\
\hline
\end{tabular}


To determine the extent that one will comprehend requires two variables for each rule: Attention and Noise, linked by ANDs. Although there are numerous ways that the variables can be combined if all levels are in play, a little reflection suggests that good coverage of conditions likely to occur can be covered by the seven rules given in the table above. There could be many more rules. However, this example calls only for those that are essential to understanding a given situation. (More rules can be added later, if needed.)

What is needed now is knowledge of how to use the rules and the consequence blocks to describe the level of understanding for a specific situation. This is done by applying the rules to obtain a consequence membership function. The resulting membership functions are chosen to reflect the conclusion of each rule, as shown in the following figure:

\section{Antecedent Membership Functions}

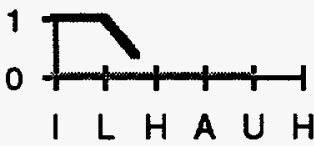

IF

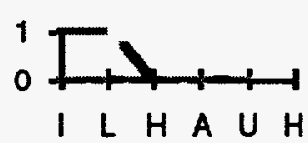

IF

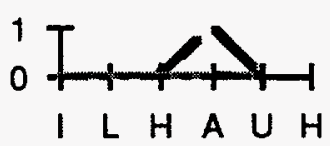

IF

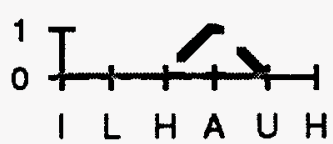

IF

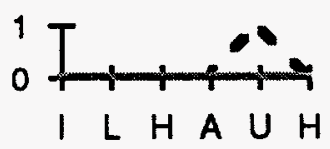

IF

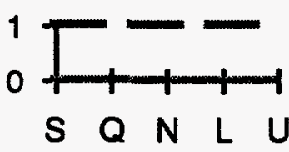

AND

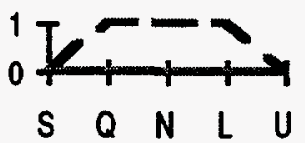

AND

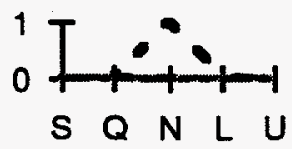

AND

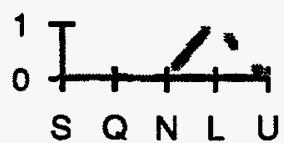

AND

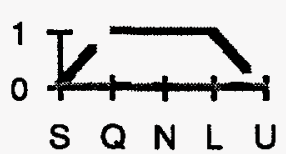

AND

\section{Consequence Function}

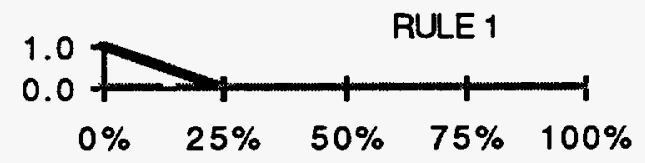

THEN

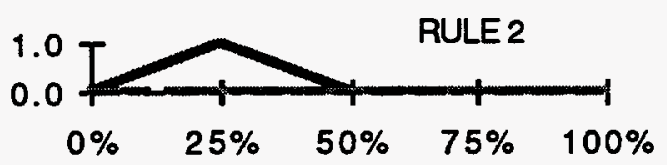

THEN

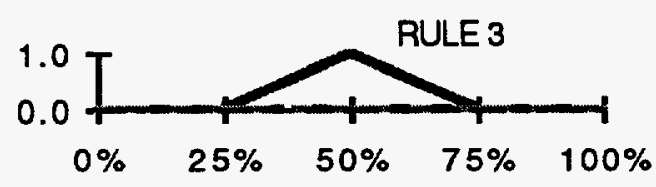

THEN

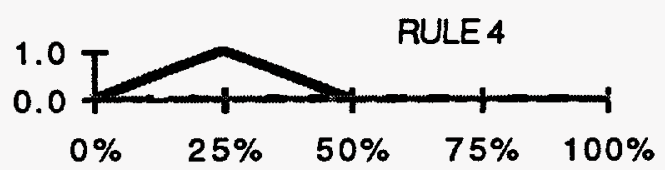

THEN

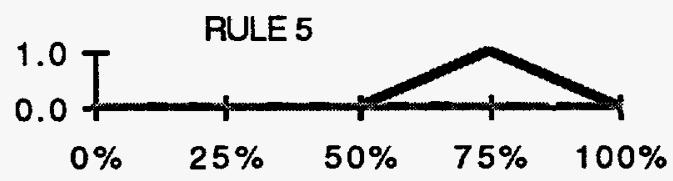

THEN 


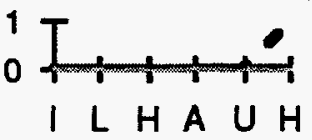

IF

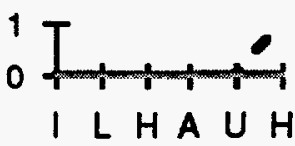

AND

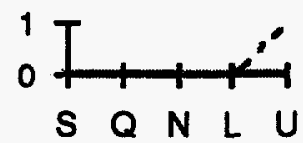

THEN

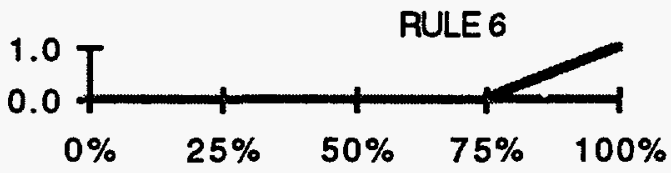

S $Q N L U$

$0 \% \quad 25 \% \quad 50 \% \quad 75 \% \quad 100 \%$

\section{T}

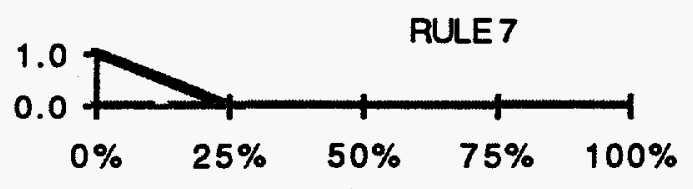

THEN

The logic that is often applied to describe the action of the inputs values on the consequences is a set of rules and their associated consequence membership functions. Applying this logic requires a procedure that defines how much importance (weight) is given to each of the consequence memberships functions. The Logical Product is used to describe the weighting. The basic logical operations of NOT (negation), AND (conjunction), and OR (disjunction) can be used to define the logical product. Most applications involve conjunction; that is, taking the minimum of two values. The logical product is calculated by setting the consequence (THEN) member function at the level of the lowest value of the antecedent (IF ... AND) membership functions. For example, if one antecedent function is set at 0.4 and another is set at 0.6 , then the consequence membership function for that rule will be set at 0.4 .

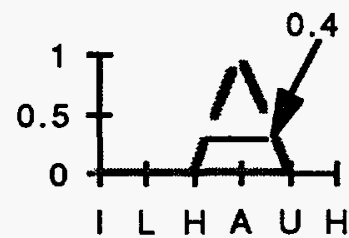

IF

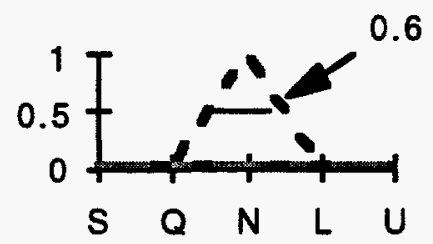

AND

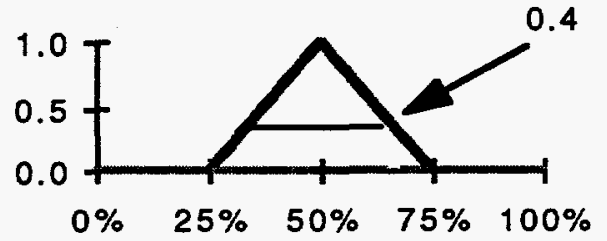

THEN

If the lowest value is zero, then the consequence membership will also be zero. Another approach, that is more logically consistent, is to take the product of the weights as the weight of the consequence function. 


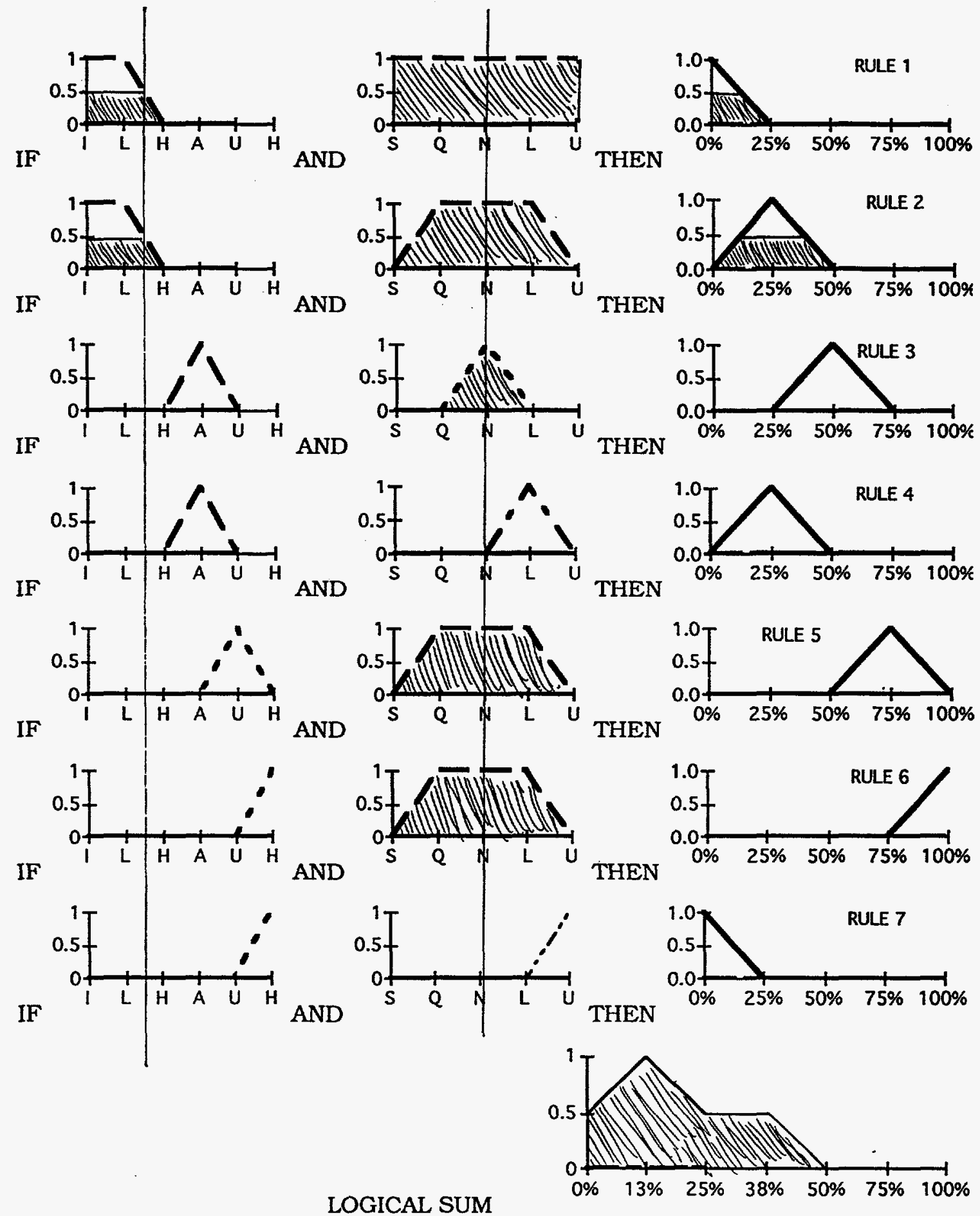

Now the question is, what is to be done with the shaded area in the consequence membership function? Of course, in the real world, there is never a condition where only one rule 
(one consequence) applies. What usually happens is that a person will be somewhere on the scale describing a variable important to the process in which he is interested. In this example, the variables would be the person's attention level and the loudness of the noise of his environs. As an example, consider that a person is about half-way between Looking and Hearing on the attention scale and that the noise background is normal. If the axes and scales have been carefully aligned, a vertical line can be drawn through all of the antecedent functions, as shown in the above figure. Using the rule that the minimum value of the antecedent function is the weight factor, the consequent functions are formed as shown. Note that only rules one and two make a contribution. What is to be done with this information to establish the "Total" consequence?

Obtaining the "Total" consequence (the overall system response) requires establishing a way to use the information contained in the consequence membership functions. First, review what has been done up to now. A rule has been used that infers a conclusion. In terms of the above discussion, premises have been established that are statements of conditions contained in the antecedents. Using the process described above, the premises lead to conclusions, which are called consequences; that is,

$$
\begin{gathered}
\text { premise } \longrightarrow \longrightarrow \text { antecedent, } \\
\text { conclusion } \longrightarrow \longrightarrow \text { consequence. }
\end{gathered}
$$

When describing a set of conditions in premises that must be met before something can happen in the consequent set, fuzzy knowledge has been translated into a mathematical statement (the IF ... AND ... THEN function). Thus:

membership in the "conclusion fuzzy set" is conditional on membership in the "premise fuzzy set." The "premise fuzzy set" alters membership in the "conclusion fuzzy set," based on the truth of the premise.

Now that the conclusion has been established, how is it used?

The process of turning the consequent membership functions into a useful result is called de-fuzzification. The simplest de-fuzzification, and the one that is appropriate to the level of complexity of our system, is to sum all of the conclusion membership sets into one grand, logical 
conclusion membership set. Following common practice, we will call this the logical sum, which is the graphical sum of the areas in the conclusion membership sets.

To illustrate the steps outlined above, consider the case of the example on Understanding. As seen, if the attention variable is about half-way between the Looking and Hearing and the noise level is normal, only rules one and two contribute. Their sum, the logical sum, is shown at the bottom of the consequent membership column. To de-fuzz this, one can take either the value of the comprehension variable at the maximum height of the logical sum or the value of the centroid of the area of the conclusion logical sum membership set.

For a domain, $\mathrm{D}$, of a fuzzy set's membership function, $(\mu(\mathrm{x}))$, the centroid, $\langle\mathrm{x}\rangle$, is given by:

$$
\left\langle x>=\frac{\int_{D}^{D} x \mu(x) d x}{\int_{D} \mu(x) d x}\right.
$$

In this case, the value is $1 / 8$, for both the maximum height and the centroid methods. The question now is, how to interpret this value? This could be associated with the fraction of the information presented that is retained by the listener or it could be the probability of the listener understanding what was said. This is where an expert enters the picture. It is the expert who will give the best interpretation. Of course, experts can disagree.

Naturally, if one of the antecedent variables changes, then the process is recomputed and a new comprehension level is found. In practice, the fuzzy processing could be occurring hundreds of times a second, and an average over time would be needed to give an overall estimate of comprehension. 


\section{FUZZYLOGIC OF A RISK-BASED GRADED APPROACH}

Often a graded approach is needed to define when standards/requirements should be applied to a situation at Sandia to insure that a criterion is met. In the simplest case, one must have a lower level of a requirement (for example, the failure rate of a component), below which the item/process is acceptable. If this is the only requirement, then the graded approach degenerates into the simple "go/no-go" logic of a computer-like decision. More often, though, the situation involves a critical item/process that is probabilistic. As a first illustration, consider the case in which the probability is a member of the fuzzy sets described by low, medium, and high. Of course, one must use the expert knowledge of specialists to define these membership functions. This might be assigned an antecedent membership functional of the form:

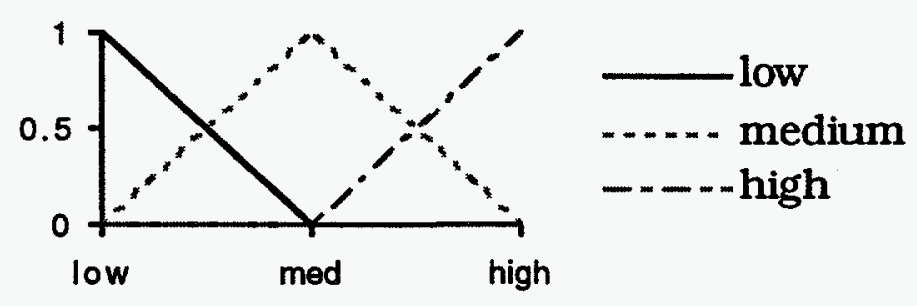

However, the use of the item/process can result in consequences that will affect the success of a program. These consequences are an additional antecedent membership functional. Again, consider this to be a three-level function of low, medium, and high. To illustrate a type of premise/antecedent that might require evaluation, consider the health risk of using a defective part, such as a bolt. Depending upon where and how the bolt is used, injury from using the bolt might be classified (with examples) as:

$$
\begin{aligned}
& \text { low - a cut finger, } \\
& \text { medium - loss of function, } \\
& \text { high - death, }
\end{aligned}
$$


with a form of:

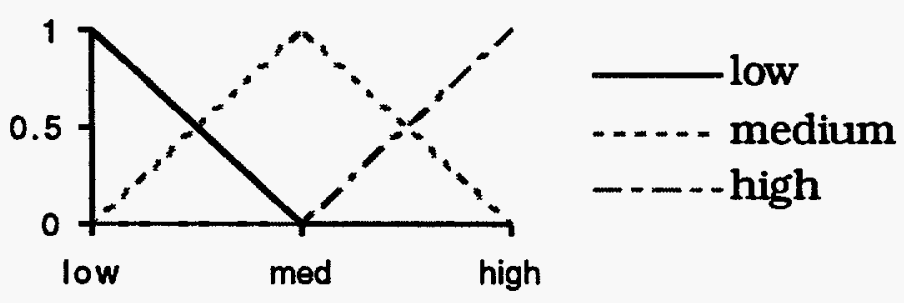

These antecedent membership functions are the IF...AND part of a set of rules. In terms of a program objective, there are probably three types of consequences. They are personnel injury, cost impact, and contamination $(E S \& H)$. Each will have a consequence that affects the program's successful completion. A possible membership function for personnel injury was described above. A similar set of membership functions for cost impact and ES\&H could be:

cost impact:

low - a few pennies or dollars

medium - a few percent of the amount of the contract

high - greater than $10 \%$ of the amount of the contract

\section{$\underline{E S \& H \text { (contamination): }}$}

low - from no contamination to very minor

medium - less than acceptable (legal?) levels

high - greater than acceptable (legal?) levels

or

low - less than acceptable (legal?) levels

medium - greater than acceptable (legal?) levels up to twice the acceptable (legal?) levels

high - greater than twice the acceptable (legal?) levels 
The next step is to establish the consequence membership functions, that is, the THEN in the IF..AND...THEN rules. ${ }^{2}$ Return to the example of suspect bolts. The two antecedent functionals are failure rate and injury. One set of rules might be:

\begin{tabular}{|c|l|l|}
\hline Rule & \multicolumn{1}{|c|}{ Premise Block } & \multicolumn{1}{c|}{ Conclusion Block } \\
\hline 1 & $\begin{array}{l}\text { IF failure rate is low AND possible } \\
\text { injury is low }\end{array}$ & THEN the consequence is low \\
\hline 2 & $\begin{array}{l}\text { IF failure rate is low AND possible } \\
\text { injury is medium }\end{array}$ & THEN the consequence is low \\
\hline 3 & $\begin{array}{l}\text { IF failure rate is low AND possible } \\
\text { injury is high }\end{array}$ & THEN the consequence is medium \\
\hline 4 & $\begin{array}{l}\text { IF failure rate is medium AND } \\
\text { possible injury is low }\end{array}$ & THEN the consequence is low \\
\hline 5 & $\begin{array}{l}\text { IF failure rate is medium AND } \\
\text { possible injury is medium }\end{array}$ & THEN the consequence is medium \\
\hline 6 & $\begin{array}{l}\text { IF failure rate is medium AND } \\
\text { possible injury is high }\end{array}$ & THEN the consequence is high \\
\hline 7 & $\begin{array}{l}\text { IF failure rate is high AND possible } \\
\text { injury is low }\end{array}$ & THEN the consequence is medium \\
\hline 8 & $\begin{array}{l}\text { IF failure rate is high AND possible } \\
\text { injury is medium }\end{array}$ & THEN the consequence is high \\
\hline 9 & $\begin{array}{l}\text { IF failure rate is high AND possible } \\
\text { injury is high }\end{array}$ & THEN the consequence is high \\
\hline
\end{tabular}

These rules can be represented graphically as:

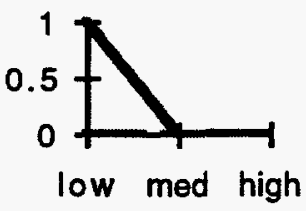

IF

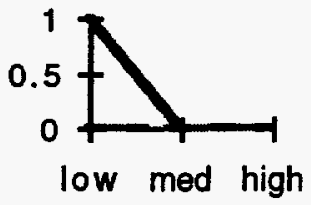

IF

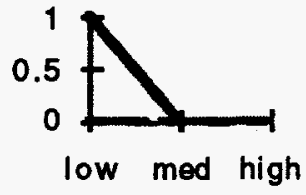

AND

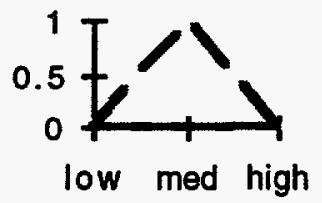

AND

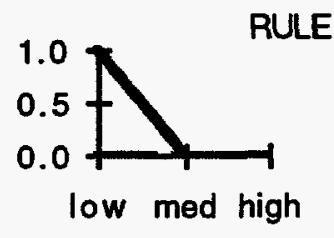

THEN

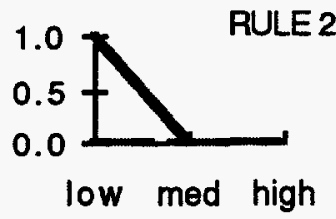

THEN

${ }^{2}$ We are considering only the case of two antecedent functionals. However, it is possible to have three or more. In a later report, this will be considered. 


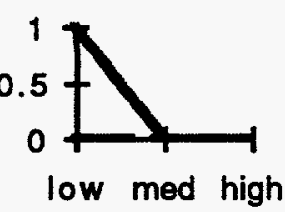

IF

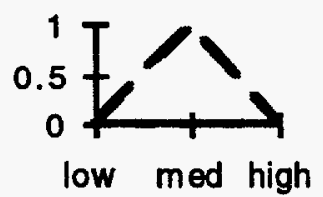

IF

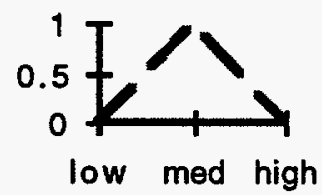

IF

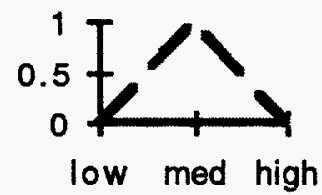

IF

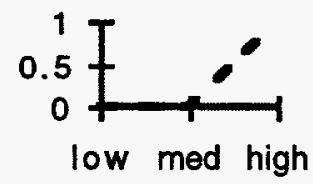

IF

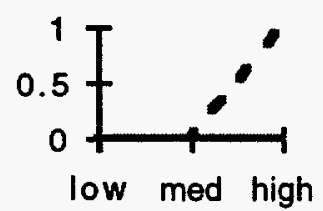

IF

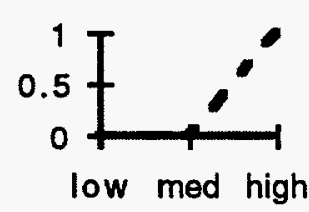

IF

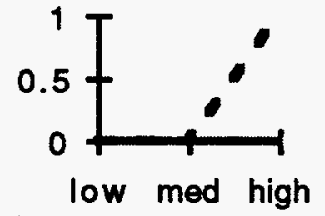

AND

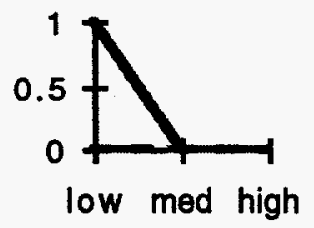

AND

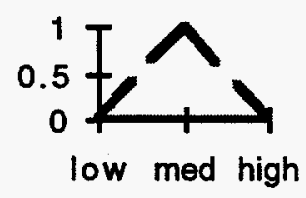

AND

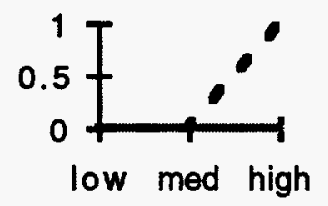

AND

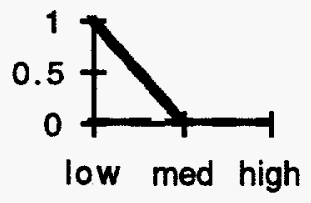

AND

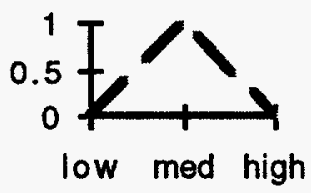

AND

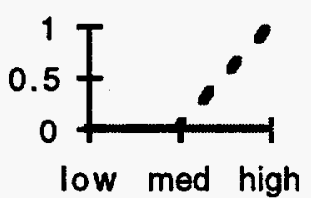

AND

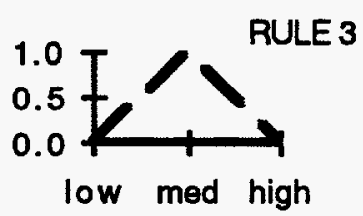

THEN

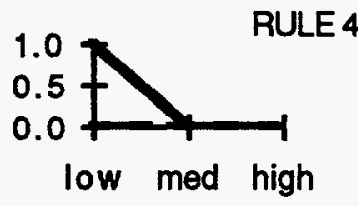

THEN

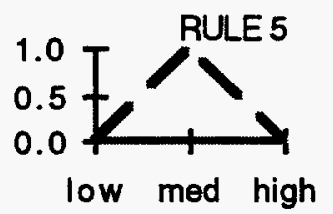

THEN

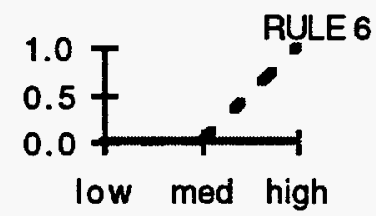

THEN

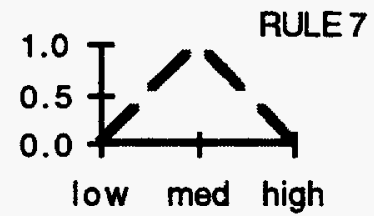

THEN

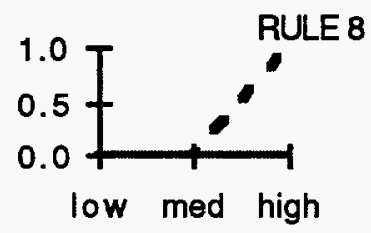

THEN

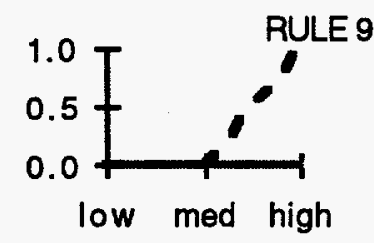

THEN 
The advantage over a simple application of an off/on set of rules now becomes a bit clearer. Continue the example. If, in a specific application, the failure rate of the suspect bolt is determined to be a fourth of the way between medium and high, and the possibility of injury is Low to Medium, the result would be the logical sum shown below.

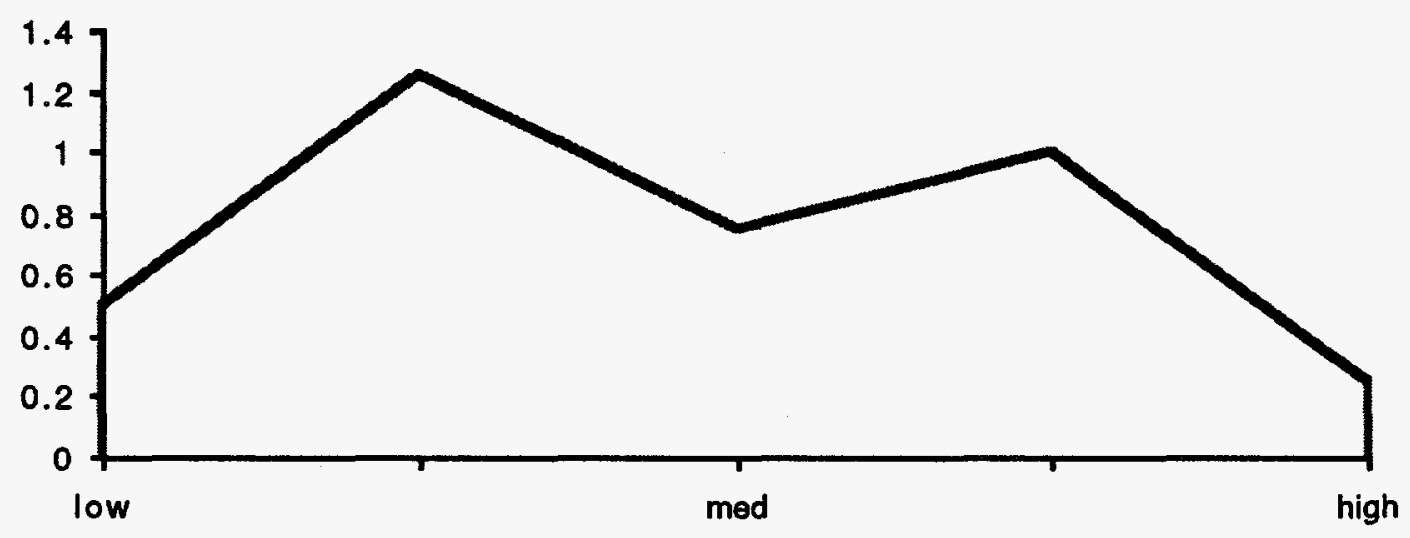

If low is given a value of 0.0 , medium a value of 0.5 , and high a value of 1.0 , one can find an average value. The average value ${ }^{3}$ of 0.4 is a reflection of the real world. A simple, bipolar on/off analysis would have been ambiguously placed, either in the low or medium consequence bin, depending on how membership in the failure rate and injury categories is assigned. This value, 0.4 , allows evaluation of needed action with much greater confidence. It provides the decision makers with an estimate of the consequences of their action. This estimate reflects a careful consideration of those aspects, within a structured and analytic framework, that are considered deterministic for this specific case. If desired, a larger and expanded antecedent membership functional base can be added easily. The people actually using the system are the ones who should be making the decision to expand the base. Note that, once the system is set up, it guarantees that the same basis is applied to each case. This helps to eliminate one of the major problems of the graded approach, namely, an inconsistent judgment caused by different, individual evaluations. ${ }^{4}$

${ }^{3}$ Be careful. Using peak values will give a different value. This value is obtained using the centroid method.

${ }^{4}$ Currently, I am working on a program that will be universally available to the worker in the field. The concept of it is that by answering a few simple questions, a field worker will be able to compute the fuzzy logic and an answer that will be automatically documented. 


\section{CONCLUSION}

The technique introduced in this report has considerable power and could be made to be rather complex, but the actual application at SNL to the selection of a set of necessary and sufficient standards/requirements is relatively straight forward.

All one needs to do is identity the input variables, establish their membership

functions, use expert knowledge to construct consequence rules and their

associated consequence membership functions, acquire the logical sum and de-

fuzz it by finding the centroid.

The entire process can be summarized by the following simple diagram:

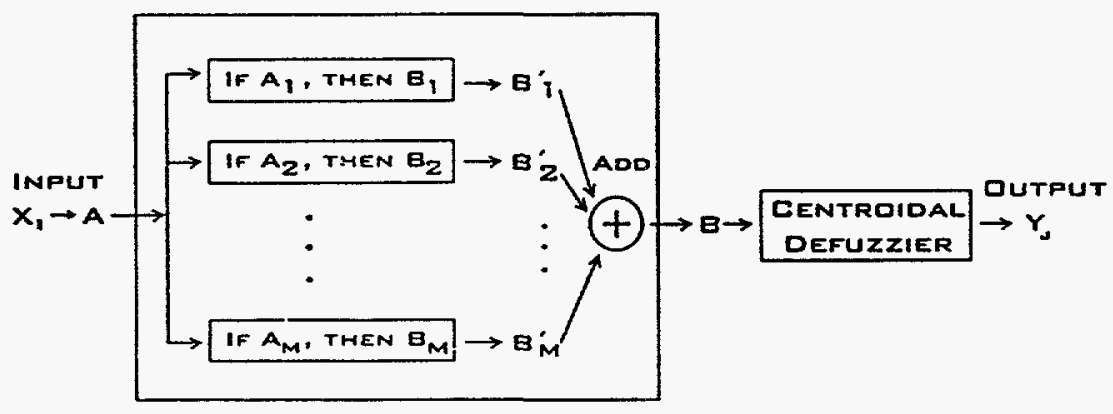

Fuzzy Logic

The next report will discuss the mathematical foundations of this approach and expand the technique to include more general premise blocks. The third report will present software for simple use of this technique at SNL. 


\section{REFERENCES}

(1) T. Masters, Practical Neural Network Recipes in C++, Academic Press (1993).

(2) J. D. McCawley, Everything that Linguists have Always Wanted to Know about Logic, Univ. of Chicago Press (1981), Chicago. 


\section{DISTRIBUTION:}

1 Pat Finley

Lockheed Martin

P.O. Box 2009

Oak Ridge, TN 37831-8241

1 Larry Andrews

Los Alamos National Laboratories

ES\&H Institutional Affairs Office

MS K491

Los Alamos, NM 87545

1 Don Sandstrom

Los Alamos National Laboratories

ISBM

MS C303

Los Alamos, NM 87545
C. Meyers

S. Binkley

C. A. Lombana

D. Engi

S. S. Narath

L. Bertholf

A. H. Guenther

R. A. Adams

C. A. Arana

F. P. Armijo

R. M. Baehr

D. E. Bishop

D. Bray

B. A. Fleming

W. R. Follett

A. J. Givens

L. A. Lauriano

J. R. Madrid

I. R. Mitchell

J. Morales

J. S. Ortega

D. B. Ragland

J. L. Ratliff

F. A. Rivera
MS 1436

1393

1380

1379

1378

1375

1370

1367

1367

1367

1367

1367

1367

1367

1367

1367

1367

1367

1367

1367

1367

1367

1367

1367
Laboratory Directed R\&D Dept., 4523

Washington Operations Dept., 4531

Business Analysis Dept., 4525

Strategic Initiatives Dept., 4504

Strategic Business Development Dept., 4524

Coporate Planning \& Strategic Business

Development Center, 4500

Alliances Dept., 4533

Laboratory Assessment Dept., 4545

Laboratory Assessment Dept., 4545

Laboratory Assessment Dept., 4545

Laboratory Assessment Dept., 4545

Laboratory Assessment Dept., 4545

Laboratory Assessment Dept., 4545

Laboratory Assessment Dept., 4545

Laboratory Assessment Dept., 4545

Laboratory Assessment Dept., 4545

Laboratory Assessment Dept., 4545

Laboratory Assessment Dept., 4545

Laboratory Assessment Dept., 4545

Laboratory Assessment Dept., 4545

Laboratory Assessment Dept., 4545

Laboratory Assessment Dept., 4545

Laboratory Assessment Dept., 4545

Laboratory Assessment Dept., 4545 
G. A. Sachs

D. Serna

L. D. Sickles

G. M. Urquhart

30 J. R. Wayland

1 K. W. Hanks

1 J. W. Bryson

\section{N. F. Schwers}

1 D. Hoffman

1 J. C. Costales.

1 A. C. Davis

1 D. G. Schueler

1 T. R. Schmidt

1 J. L. Chamberlin

1 C. R. Martin

1 M. H. Martinez

1 B. Lovejoy

1 V.L. Dugan

1 B. Apodaca

1 P. E. Shoemaker

1 J. C. Cummings

1 G. W. Kuswa

1 N. M. Briscoe
Laboratory Assessment Dept., 4545

Laboratory Assessment Dept., 4545

Laboratory Assessment Dept., 4545

Laboratory Assessment Dept., 4545

Laboratory Assessment Dept., 4545

Management Systems Deployment Dept., 4543

Isotope Project \& Compliance Initiatives

Dept., 9361

Nuclear Facilities \& Diagnostics Dept., 9362

Logistics Management Center, 7600

Storage Services Dept., 7618

Integrated Management Systems \& Assessment Dept., 4541

Integrated Management Systems \& Assessment Dept., 4541

Price Anderson Rules/SRID Dept., 4544

Integrated Management Systems \& Assessment Dept., 4541

Integrated Management Systems \& Assessment Dept., 4541

Integrated Management Systems \& Assessment Dept., 4541

WFO Operations Dept., 4532

Corporate Planning \& Strategic Business

Development Center, 4500

Investment Resources \& Customer Coordination Dept., 4522

Laboratory Planning \& Evaluation Dept., 4512

Strategic Investments Coordination Dept., 4521

Strategic Investments Coordination Dept., 4521

Administrative Processes, 4500

Central Technical Files, 8523-2

Technical Library, 4414

Print Media, ' 12615

Document Processing, 7613-2

For DOE/OSTI 